Human Journals

Review Article

November 2020 Vol.:19, Issue:4

(c) All rights are reserved by Ashish Akshay Bedi et al.

\title{
A Review on Current Trends of Anti-Tubercular Drugs and Challenges in Eliminating Tuberculosis
}

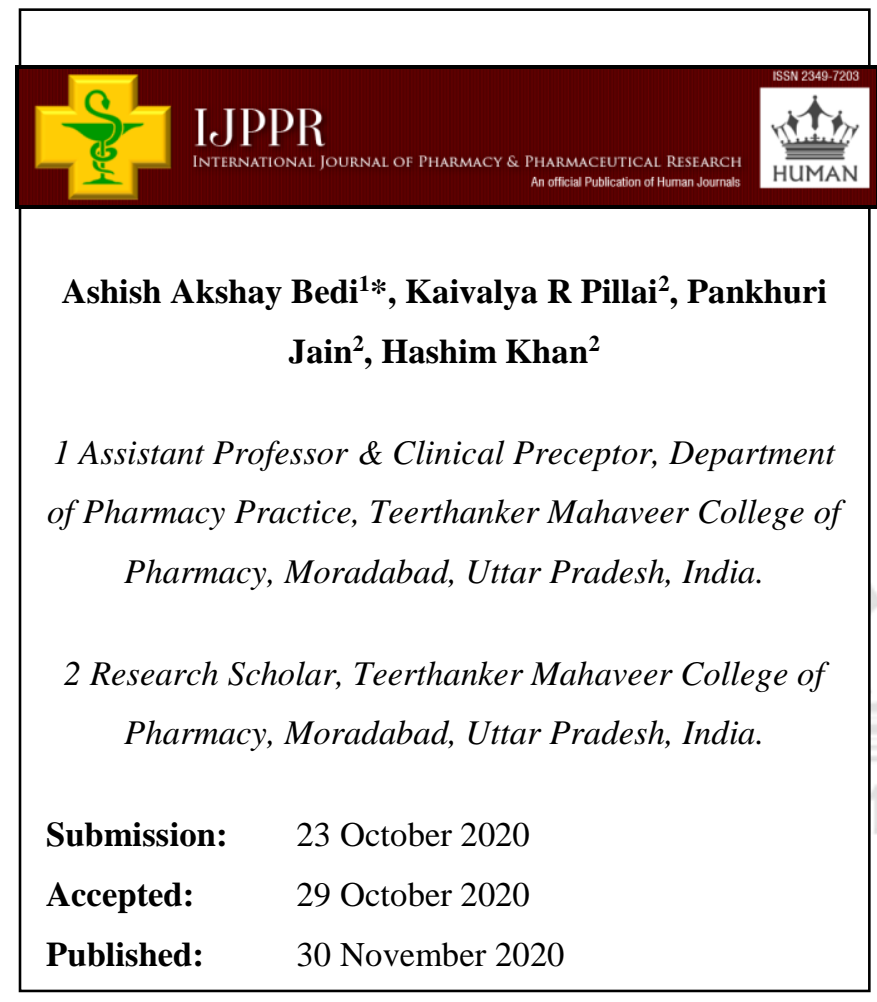

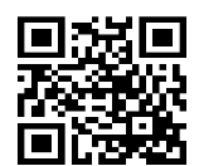

www.ijppr.humanjournals.com
Keywords: DUE, Prescribing Patterns, Tuberculosis

\section{ABSTRACT}

Tuberculosis (TB) is a communicable disease that is a major cause of ill health and a threat to health worldwide. Tuberculosis accounts for one of the top 10 causes of death worldwide and the leading cause of death from a single infectious agent which is $\mathrm{M}$. tuberculosis (ranking above HIV/AIDS). If the patients are diagnosed on time and treated with first-line antibiotics for 6 months, most people who develop TB could be cured and onward transmission of infection could be reduced. Sustainable Development Goals Target 3.3 includes eliminating the TB epidemic by 2030 . The End TB Strategy explains milestones (for 2025) and targets (for 2030 and 2035) for depletion in TB cases and deaths, 90\% reduction in the number of TB deaths, and an $80 \%$ reduction in the TB prevalence rate compared with levels in 2015 are the targets for 2030. Evolution of Tuberculosis as Drug-resistant TB continues to be a public health threat. About half a million new cases of rifampicin-resistant TB (of which 78\% had MultiDrug-Resistant TB) were reported in 2018. India (27\%), China (14\%), and the Russian Federation (9\%) bear the largest share of the global burden of TB patients. Diagnosis of MDR/RR-TB needs bacteriological confirmation of TB and testing for drug resistance using rapid molecular tests, sequencing technologies, or culture methods. Treatment requires a course of second-line drugs for at least 9 months and up to 20 months, held by counseling and monitoring for adverse events. Newer agents like Bedaquiline, Delamanid, Linezolid may be the key for the further treatment of MDR and XDR-TB although they are required to prove their safety in the treatment through proper monitoring and evaluations. The DUE study of TB medications helps in monitoring, evaluating, and make necessary modifications to the prescribing habits to achieve rational and cost-effective treatment. Although there are many challenges to tackle in front of the world if this has to be eliminated then the whole world has to come together and put its efforts towards ending it. 


\section{www.ijppr.humanjournals.com}

\section{INTRODUCTION}

Tuberculosis is one of the major causes of death because of its communicable nature. It is counted as one of the top 10 causes of death worldwide as well as it is ranked number one in causing death from a single infectious agent above HIV/AIDS. [1] This disease has become more challenging after it has evolved into another stage called Drug-Resistant Tuberculosis.

This evolution remains one of the biggest public health challenges of $21^{s t}$ century. [2] It was already troubling to deal with Multi Drug-Resistant Tuberculosis that the advanced form of Drug-Resistant Tuberculosis emerged such as Extensively Drug-Resistant Tuberculosis (XDR-TB) and Total Drug-Resistant Tuberculosis (TDR-TB) and became the more lethal level of the disease. [3] Half of the cases of MDR/RR-TB are attributed to the following three countries, which are: India (24\%), China (13\%), and the Russian Federation (10\%). As for the newer problems newer solutions are required, hence, newer drugs have been undergoing clinical trials for a long period and some newer drugs are found effective and less interactive with other drugs, therefore causing fewer adverse reactions. Bedaquiline (BDQ) is accounted for the treatment of MDR-TB and XDR-TB with the combination of other drugs such as Pyrazinamide, Ethambutol, Ethionamide, Linezolid, etc. according to the guidelines. BDQ has passed the clinical studies and shown its worth in the case of effectiveness but it still has to be evaluated very carefully for their adverse events before they are used more widely. $[4,5]$ The other newer drug Delamanid when given with Bedaquiline shows very few adverse events and high efficacy in a salvage regimen. Although this combination is used when very few treatment options are left for the patient. [6]

When a drug is prescribed to a patient it comes with both kinds of effects, some beneficial therapeutic effects as well as some adverse effects. There are lots of adverse events that are caused by the anti-tubercular drugs which include: peripheral neuropathy, transient increase in LFT's, hyperuricaemia, QTc prolongation, ototoxicity, arthralgia, dermatitis, etc. [7] Some ADRs are side effects of the drugs but some reactions like ototoxicity are caused due to lack of certain guidelines to observe the patients administering aminoglycosides used in the treatment of MDR- TB. ${ }^{[8]}$ When during a treatment the patient suffers from any ADR it is important to evaluate the prescription and the extent of the adverse reaction the patient is suffering. For this kind of evaluation of the patient's condition, their prescription has to be carefully monitored throughout the treatment. Drug Utilization Evaluation is a process which 


\section{www.ijppr.humanjournals.com}

makes sure that the current standard of care is accomplished by the pharmaceutical therapy, inhibits medicine-related problems, encourage most favorable medication therapy, recognize certain medicine use problems that need more evaluation, improves liability in the medication use process, manage pharmaceutical cost, design guidelines for suitable medicine use, explain thresholds for quality of medicine use.

Eliminating tuberculosis is one of the biggest challenges for the world for a long period. The UN countries have unified to oppose and terminate Tuberculosis by 2030 under Sustainable Development Goals. Though, focusing on the generality of TB, India has to achieve this target at least five years ahead of the other countries as India contributes around $23 \%$ of the total active Tuberculosis patients and $27 \%$ of the unreported cases around the globe. Regardless of various steps taken by the Indian Government, many challenges are still there to be tackled to reach the goal. [9]

\section{Evaluation of Anti-tubercular Drugs' Utilization}

As it is stated that Tuberculosis is one of the biggest cause of death worldwide and with its modification such as getting resistant towards essential first-line drugs it is very important to monitor and evaluate the treatment of the patients to know about the present trend and condition of the disease and how it must be treated to eliminate it. For this monitoring Drug Utilization Evaluation is the recommended process to get a win over this endemic disease. This process has to be implemented all over the world but especially DUE has to be strictly processed in high burden countries like India, China, and the Russian Federation. Although still after efforts such as the PMDT program DR-TB cases are still uncovered especially in private sectors. ${ }^{[10]}$ The poor outcomes of the treatment of the disease could be highlighted with an explanation that only $55 \%$ of the prescriptions held to the recommendations by the guidelines, according to a study done in Taiwan. ${ }^{[11]}$ The first challenge to tackle the disease is to find out the positive patient. Therefore, for the best positive results in TB patients, the basic necessity is to appropriately diagnose the patients and rationally prescribe the antitubercular drug regimens according to the guidelines. ${ }^{[12]}$ We say that MDR-TB is the hurdle of reaching to eliminate the goal of eliminating TB till 2025, but what caused the condition of arising of this resistance? This development of MDR-TB is the result of the irrational use of anti-tubercular drugs. Pre-mature introduction of certain drugs may induce drug resistance. That is why it is necessary to stick to the regimen provided by the guidelines so that fewer 


\section{www.ijppr.humanjournals.com}

cases lead to the complex level of the disease and could be treated in earlier phases. ${ }^{[13]}$ The first step to treat TB is to think about it and spread awareness between physicians as well as laypeople about it. Early diagnosis and quick initiation of the treatment will lead to the best outcome and special care should be taken of not spreading the disease further through that infected person. [14] According to a study in El-Minia governorate, the diagnosis of the patients is still a complication due to the lack of diagnostic labora- tories, although the treatment success rate has been increased $(93.87 \%)$ and failure rates have decreased after the execution of DOTS there. [15] Rationalizing the drug therapy and sticking to the NLEM with the least use of the PPI and multivitamins where it is not necessary and giving priority to generic drugs more than branded can decrease the cost of treatment as well as increase the probability of efficacy with fewer side effects. [16] Consumption of alcohol, selection pressure from previous treatment, and smoking are some demonstrated risk factors that are increasing the development of MDR-TB and is more commonly found in HIV positives. This makes the surveillance to be more impactful and careful in the TB control program. [17] For a successful treatment, the focus should be on the direction to use such drugs from which either the resistance of organism is suppressed towards antibiotics or play a synergistic role to other anti-TB drugs. By strictly following the criteria the possibility of MDR-TB might get suppressed. [18] In Karnataka, due to the obstacle of drug stock-out, there was a barrier in prioritizing 'IPT initiation', and to overcome this situation and reaching the target we have to meet the need of the supply chain and manage it properly. ${ }^{[19]}$ It has been proven that if tailored to local community conditions CB-DOT improves the treatment outcome and if this strategy is applied in low to middle-income countries this will be cost-effective and show better acceptable results. ${ }^{[20]}$ Linezolid, Bedaquiline, and Delamanid are the drugs that might play a prominent role in the treatment of MDR-TB for both adults and children according to some studies. [21] In Dakahlia governate the initiation of Directly Observed Therapy Shortcourse has guided them to a remarkable increase in treatment success $(84.8 \%)$ and the failure rate has declined since then. [22] A short-course treatment regimen including a fourthgeneration fluoroquinolone, an SLI, and CFZ are considered as successful as first-line treatment for MDR-TB patients in Niger and no relapses or failures were recorded up to 24 months after getting cured. [23] The success rate of the current regimen if administered properly with proper monitoring is accounted to be around 90-98\%. Moreover, 6 months 


\section{www.ijppr.humanjournals.com}

regimen for drug-susceptible $\mathrm{TB}$ and six or seven drug regimen for XDR-TB or MDR-TB were recommended and accounted as successful treatments with fewer complications and recurrence. ${ }^{[24]}$ For additional adjuvant anti-TB drugs, metformin and statin are required to be further authenticated through well-controlled randomized clinical trials. Due to their immunomodulatory properties, they increase the therapeutic efficacy and must be surveyed more in clinical trials to prove them as promising adjunctive Anti-tubercular agents. [25]

\section{Newer Anti-tubercular Agents}

Lately this decade, remarkable progress has been made in rejuvenating the novel agents for the efficacious and less adversely reactive treatment and treatment regimen of Drug-Resistant Tuberculosis. Although a crucial challenge will be to endure and expand the funding for ongoing developmental and clinical work to assure the elimination of tuberculosis till 2030. [26] MDR-TB has brought a huge challenge in front of the world for the control of TB and is becoming a threat to TB elimination. The beginning of the problem has been the irrational and sub-optimal management of the drugs and the treatment regimen. Poor management of cases can be the birth of $50 \%$ of the new RR/MDR-TB cases. Treatment of Drug-Resistant TB has progressed greatly over the last few years, the new shorter MDR-TB regimens and expanding the availability of new drugs like Bedaquiline, Delamanid, Clofazimine, and Linezolid assure more successful treatment and therefore less death. If we don't repeat previously committed errors with the new drugs and move with proper monitoring and evaluation then we have the chance to achieve the respective target. [27]

\section{BEDAQUILINE}

Bedaquine was first accepted in 2012 for its use in the treatment of MDR-TB by the FDA. Bedaquiline belongs to the diarylquinolines class of compounds. [28] Bedaquiline is a new and compelling drug for the treatment of MDR and XDR-TB. The latest evidence proposes that tolerability is better than anticipated and the reported effect on QT interval can be controlled. [29] BDQ having amazing bactericidal and sterilizing activity against the M.tuberculosis and many NTM has exhibited magnificent efficacy in preclinical and clinical trials. When compared with placebo in patients with MDR-TB, BDQ strongly declined the duration for sputum conversion period and median CFUs. [30] BDQ administered 200mg QD for 2 months succeeded by $100 \mathrm{mg}$ QD for the remainder of a 6-month regimen seems rational 


\section{www.ijppr.humanjournals.com}

when compared to exposures associated with the labeled regimen. [31] A study held in Belarus proposed that BDQ containing regimen are highly effective and have a sufficient safety profile for patients with MDR and XDR-TB with magnificent treatment outcomes and swifter in converting cultures compared to previous regimens. [32] However, better results will be acquired if programs could ensure adequate treatment and follow up in differentiated centers with comprehensive patient support, suitable management of adverse events, free of charge treatment, tailored treatment regimens, and lung surgery when indicated. Extended treatment with bedaquiline could additionally improve treatment outcomes, although more evidence is needed. ${ }^{[33]}$ BDQ in combination with a BR can attain higher and quicker culture conversion rates in the case of MDR and XDR- TB. Before the more widespread use of this drug, it has to be cautiously evaluated of adverse events, particularly monitoring of hepatotoxicity and cardiotoxicity.

\section{DELAMANID}

Delamanid is a drug of the nitroimidazole class accepted by the European Medicines Agency for the treatment of MDR-TB. In between other drugs of $\mathrm{TB}$, Delamanid shows minimum inhibitory concentration and is established to be active against both DrugResistant and Drug-Sensitive M.tuberculosis. [28] Delamanid was correlated with an increase in sputum-culture conversion at 2 months among the patients with MDR-TB. This recommends that Delamanid could intensify treatment options for MDR-TB. [34] The addition of Delamanid in the regimen of MDR-TB is a major step in the fulfillment of the 2030 goal. Many more clinical trials have to be performed and many more evaluations have to be done to ensure the safety of this drug and its role in the regimens in pediatric populations, HIV co-infection, and regarding combination with bedaquiline. [35] Till now clinical efficacy data of Delamanid is limited but reassuring. Dela- manid till now is proved to be well tolerated and with a warning of plausible QTc prolongation, appears to have a beneficial safety profile as compared to second-line drugs. [36]

\section{Adverse Effects and Toxicities}

An adverse drug reaction (ADR) is an undesirable or injurious reaction experienced succeeding the administration of a drug or combination of drugs under normal conditions of use and is questionable to be related to the drug. Adverse effects are pretty common when it comes to 


\section{www.ijppr.humanjournals.com}

drugs but the key is to treat a patient with the least adverse effect and maximum efficacy. In a disease like Tuberculosis, where there is the use of a high dose of antibiotics there might be some incidence of adverse effects which may be common or severe. Prescription of drugs according to the guidelines provided leads to less incidence of adverse effects with proper monitoring of the patient during the treatment regimen. DOTs are considered safe, effective, and have less incidence of adverse effects but an expanded prevalence of tuberculosis increases the number of patients at risk of adverse events. Monitoring is very necessary for all the tuberculosis treatment regimens. [37] All tuberculosis patients must be routinely investigated for the incidence of Peripheral Neuropathy as it is a very common condition found in them. Hence, they must be closely monitored throughout their disease span. The presence of the neuropathic symptoms must be made understand to the patients and they must be asked to report if they undergo any symptom so that it could be treated as soon as possible. [38] The management of MDR-TB has been observed to be complex with challenging reasons being extended 24-27 months and high toxicity profile of SLDs. $46.9 \%$ of the patients included in a study were experiencing adverse events which were mostly in the intensive phase of the treatment of MDR-TB. [39] The most common adverse effects caused by the SLDs were gastrointestinal such as gastritis, vomiting, and reduced appetite. 25\% Peripheral Neuropathy was caused due to Ethionamide, 25\% Depression, and 20\% Suicidal tendencies were caused due to Cycloserine, $15 \%$ Ototoxicity was caused due to Aminoglycosides which was irreversible after discontinuation. ${ }^{[40]}$ ADRs were common in patients of MDR-TB on DOTs-Plus regimen. It could be decreased and well maintained only by proper monitoring of the patients and keeping the account of the clinical parameters. This may help in enhancing the adherence and eventually quality of patient care. [41] Evaluation of certain studies' results shows that Bedaquiline is a comparatively welltolerated drug since its cessation occurred only in $3.4 \%$ and $0.6 \%$ of patients due to ADE. Although, if BDQ is prescribed then strict monitoring of ECG is mandatory. Delamanid as well when administered to the patients in a study no single cause of the fatal cardiac event was reported. [42, 43] Administration of anti-TB drugs leads to changes in hematologic parameters and liver enzymes. Hazardous effects are imposed on the patient's liver, which may lead to hepatotoxicity and is one of the problems to the patients. [44] All the first-line drugs have a common side effect on the liver leading to hepatotoxicity. Malnutrition, advanced age, female sex, alcoholism, and pre-existing liver disease can additionally 


\section{www.ijppr.humanjournals.com}

accelerate drug-induced hepatitis during the TB treatment. Patients suffering from both HIV and Tuberculosis have more probability of developing ATDH, probably due to altered activities of oxidative pathways. [45] When a TB patient takes more than 4 anti-TB drugs simultaneously then there is a risk of having a negative influence on sexual function too. [46] Fluoroquinolones use has an enhanced risk of causing adverse effects. A study stated that the prevalence of ADRs was more succeeding FQ use than the utilization of other antibiotics for a similar condition. The safety profile of FQ must be taken into consideration by the physician before its use. [47] Some common adverse reactions to fluoroquinolones are such as advanced age, metabolic disturbances, dysglycemia, QTc prolongation, tendinopathy, CNS effects like insomnia, dizziness, hallucinations, delirium, etc. [48] In MDR-TB, such agents are used in the drug regimen which are much more toxic than the first-line drugs. There have been reports of mania and psychosis in the treatment of MDR-TB, induced by the drug cycloserine. This drug has been blamed for inducing psychiatric adverse effects on the patients. Close monitoring of psychiatric side effects has to be done in patients administering MDR-TB regimen including cycloserine. [49]

\section{Drug Resistance: A Huge Challenge}

Tuberculosis is considered to have a great global impact, but because it is preventable and treatable it makes the fight against this disease an extremely cost-effective interference. Drug resistance is a consequence of unprompted gene mutation in $\mathrm{M}$. tuberculosis that provides the bacteria resistant to the most commonly used anti-TB drugs. The non-compliance with the treatment regimens is warned as the first cause. ${ }^{[50]}$ Although the planning of achievement of goals may get hindered because of the spread of the Multi-Drug Resistance TB. The early diagnosis and treatment of drug-affected or single drug-resistant TB is a beneficial strategy for inhibiting the incidence of MDR-TB. [51] TB cannot be eliminated globally until it is terminated from India. This is because India is the highest carrier of the disease. About 1.9 million new cases are added every year, in which more than half a million are supposed to be undiagnosed. India also has the high- est prevalence of MDR-TB. [52] Isoniazid is one of the important drugs used in the treatment of tuberculosis, which we cannot stand to lose. It is less in cost, effective, has minimal adverse effects, and do not have a similar positive alternative. A study suggests that negligence and lack of concentration in Non-MDR Isoniazid Resistance can become a problem and has to be given proper vigilance over it to control TB globally. 


\section{www.ijppr.humanjournals.com}

[53] According to a study in Pakistan, the increasing incidence of FQ resistant MDR-TB patients was frightening. To control the condition few steps are very important to be taken such as to inhibit the sale of FQ without a proper prescription, making the physician aware of the condition, and immediately rationalizing the use of FQ. Other steps would be to spread awareness to the laypeople and especially the suffering patients about the disease, danger of self-medication with antibiotics, physicians should be well trained regarding the disease especially in the private and PPM sectors and make the health care system more substantial, attractive and flexible to develop people's trust in them. [54] A study showed that among HIV-negative patients without a history of previous treatment with SLD, a short, standardized treatment regimen that relied on fourth-generation fluoroquinolones merged with SLD supplemented by potentially active first-line drugs was found to be highly effective. ${ }^{[55]}$ As anti- TB drug resistance is associated with previous TB treatment, then this may be the outcome of the sub-optimal performance of the DOTS program in detecting infectious TB cases and hence, DOTS and DOTS plus needs to be strengthened and expand MDR-TB diagnostic facilities for its early diagnosis so that they can get treated without delay in Ethiopia. [56] A study stated that the clinician in-charge should interpret the number of drugs and the duration of treatment with an awareness of the restrictions mentioned. The TB patients should have better access to laboratories that can perform DST dependably to detect resistance spot on is very important. [57] The main reason for the increasing spread of drugresistant TB strains is dull medical systems, incorrectly treating drug-sensitive TB patients also magnifies resistance and the continuing transmission in communities and facilities because of less awareness. Community-based programs can enhance the condition by spreading awareness and addressing socioeconomic blockade to adherence. [58] A study stated that a short regimen was non-inferior to a long regimen concerning the primary efficacy outcome and was similar to the long regimen in case of safety when administered to the patients with rifampicin-resistant tuberculosis that was sensitive to FQ and aminoglycosides. ${ }^{[59]}$ Whereas, on the other hand, Linezolid is successful at attaining culture conversion among patients with treatment-refractory XDR pulmonary tuberculosis, although close monitoring is mandatory while the administration of Linezolid in the treatment to look after adverse events. ${ }^{[60]}$ In countries with a high burden of tuberculosis, the utilization of more quick methods for detecting the disease and molecular resistance tests, particularly Rand $\mathrm{H}$ - resistance, is exigently required. Moreover, regarding the treatment of MDR-TB and 


\section{www.ijppr.humanjournals.com}

XDR-TB, newer drugs are needed to be developed. [61] The National TB Control Program in the assistance of well-structured nationwide vigilance is needed to strengthen the treatment strategies for enhanced outcome. [62]

\section{Addressing the Factors Influencing TB Management}

When a prescription is prescribed, a lot of factors influence it. The physician in-charge considers many factors before he writes the prescription. The factors that influence general physicians' prescription are Indication of patient's condition, including the sign and symptoms, co-morbid conditions and uncertain diagnosis, physician's attributes, medication cost, insurance, and financial incentives, marketing and promotional strategies of Pharmaceutical industries, pharmaceutical's clinical effectiveness, and safety, Medication history of the patient and previous disclosure of prescribers.

Whereas, in the case of Tuberculosis, physicians don't have a vast choice of their own on the drugs they use in prescription. As the treatment is a long term and the drugs have to be used are quite on the heavier side. So if the patient has to be recovered safely with no or least side effects then they have to be treated according to the guidelines provided by the WHO and the National Guideline for the disease (if any). The factors that have to be cautiously taken into account in TB and HIV management include stigma, attitude, the status of loss to follow up, awareness of the TB transmission. [63] The factors that may contribute to poor TB treatment adherence are lack of adequate food, improper communication between patient and the prescriber, unavailability of DOTS service in nearby facilities, side effects, and pill burden of the drug. This could be taken care of through some sustained health education campaigns given to the patient, healthcare workers, patient's family, religious leaders, and traditional healthcare practitioners. [64] Health education should be provided to the most troubled population group and enhance the knowledge of the population regarding tuberculosis. ${ }^{[65,}$

66] Lack of knowledge about National and International guidelines and recommendations of health care workers and adding to that misconception regarding $\mathrm{TB}$ patients among the patients are also the points of concern. [67, 68] According to a study, in Delhi the Private Practitioners rely on the X-ray for diagnosis, and sputum examination is being ignored for initial diagnosis, treatment vigilance, and criteria for stopping treatment. The RNTCP recommended treatment regimen is not prescribed by the majority of the Private Practitioners because they are not aware of it and some are not prescribing just out of their interest. And 


\section{www.ijppr.humanjournals.com}

because of this happening, majority of patients are getting over-treated. Private Practitioners need more training and guidance for their work. [69] A study in Georgia showed that extended delay in diagnosis and detecting the disease is quite common there. For enhancing the treatment there, it is important to cease the misuse of antibiotics there and for that dispensing of antibiotics without prescription has to be banned, the groups are targeted which are at risk for the prolonged delay and warranted to reduce diagnostic delays. ${ }^{[70]}$ Other ways to improve TB treatment seeking and adherence is by undertaking stigma-reduction strategies, such as community awareness programs and the formation of social support groups to eliminate the myths and misapprehension associated with TB. [71] Eventually, increased attentiveness to not only analysis and treatment but the quality of TB healthcare services is necessary to enhance TB treatment outcome. [72]

\section{Barriers in Eliminating TB}

As the government of India has announced the plan to eliminate TB by 2025 during the Union Budget. As much as the task seems to be ambitious it is extraordinarily difficult as well as India accounts for the biggest burden of this disease globally. 27\% of the world's 10.4 new billion cases and $29 \%$ of the 1.8 million TB deaths globally. $16 \%$ of the estimated 4,80,000 new cases of MDR-TB are also accounted for by India. For achieving this furthermost India needs to invest in their health care services. The budget for India's Revised National TB Control Program (RNTCP) also needs to enhance. Now after the cost settlement, India needs to promote health education programs through different mediums and make confirm that the common people of India have the basic knowledge about the disease. Moreover, India also has to invest in the Research department of the country to evaluate more about the disease and its treatment. [73] Over $80 \%$ of the people with TB first visit the private sector, and still, there are no strict guidelines to regulate the private sector which may lead to further expansion of drug resistance. There is a foundation of incentives for private providers to advertise TB case notification and assure treatment adherence and treatment

completion. ${ }^{[74]}$ Some major challenges are also in the way of the WHO European Region in its struggle against TB. Some major restraints are the high rate of MDR-TB, Eastern countries and Central Asia suffering from the rapid increase of the HIV epidemic and thereupon the quick increase in HIV related $\mathrm{TB}$, still restricted political and financial commitment to TB control, lack of defense, communication, and social mobilization. [75] 


\section{www.ijppr.humanjournals.com}

Huge investments are needed but insufficient profit, this is a big problem in developing a new anti-TB drug as the cost of developing a drug varies from 115-240 million dollars. Time is also a big factor as it takes nearly 10 years for a drug to complete all its processing and come into the market. Although there are lots of opportunities expected in near future. New drugs as well as vaccines are ready to undergo clinical trials. The cost of clinical trials is less in India as compared to western countries. Lack of infrastructure is although a cause of concern. [76] As India has expressed its commitment to the highest level by deciding to eliminate TB by 2025, the bell is tolling on the head. It now needs the momentum of all the stakeholders from health workers, Doctors, Parliamentarians, civil society, community workers, affected patients, and everyone to fight together against this life-taking disease and fulfill the ambitious target to end TB. [77]

\section{CONCLUSION}

As it is stated globally, the elimination of Tuberculosis by 2030 is like a mission worldwide and many steps have already been initiated and are working towards achieving this goal. Although all Governments and Organisations are trying to end TB, the drug resistance of the important first-line drugs such as Isoniazid and Rifampicin has made the challenge of elimination more strenuous. Multi-Drug Resistant TB has completely begun a new chapter of this disease and its spread is making is worst. The first challenge and step have to be the spread of the knowledge about this disease to all the corners of the world to every existing person. Newer drugs have been discovered for the treatment of TB such as Bedaquiline, Delamanid, Linezolid and they are showing quite a good result to date but they are not still completely trustable on the issue of the adverse effects they cause. Adverse reactions caused by these heavy antibiotics are also very fatal at times and may cause high damage such as Ototoxicity, Peripheral Neuropathy, Depression, etc. As a solution for this, proper monitoring of the patients administered with these drugs is strictly recommended in the guidelines. For the elimination of $\mathrm{TB}$, it is also important that all the health sectors including both Government and Private are given proper latest information about the drug regimens for the treatment of tuberculosis. The research department of the country must also be strengthened and the Government should increase the investment in the health sector so that they can get better outcomes out of it.

In the end, the basic need as a weapon to eliminate this disease is proper education and the latest information provided to the common people through different means such as health 


\section{www.ijppr.humanjournals.com}

education campaigns, healthcare workers, and other healthcare institutions. So in this time of emergence to stop this disease and ultimately eliminating $\mathrm{TB}$, it is necessary that all health workers, Doctors, Parliamentarians, civil society, community workers, affected patients, and everyone to fight together against this life-taking disease and fulfill the ambitious target to end TB.

\section{REFERENCES}

[1] World Health Organization. World Health Organization. 2019;2019:1-1.

[2] Olson G, Nathavitharana RR, Lederer PA; 2019.

[3] Dalal A, Pawaskar A, Das M, Desai R, Prabhudesai P, Chhajed P, et al. Resistance Patterns among Multidrug-Resistant Tuberculosis Patients in Greater Metropolitan Mum- bai: Trends over Time. PLOS ONE. 2015;10(1):e0116798-e0116798. Available from: 10.1371/journal.pone.0116798; https://dx.doi.org/10.1371/journal.pone.0116798.

[4] Salhotra VS, Sachdeva KS, Kshirsagar N, Parmar M, Ramachandran R, Padmapriyadarsini C, et al. Effectiveness and safety of bedaquiline under conditional access program for treatment of drug-resistant tuberculosis in India: An interim analysis. Indian Journal of Tuberculosis. 2020;67(1):29-37. Available from: 10.1016/j.ijtb.2019.10.002;https://dx. doi.org/10.1016/j.ijtb.2019.10.002.

[5] Fox G, Menzies D; 2002.

[6] Sarin R, Vohra V, Singla N, Singla R, Puri MM, Munjal SK, et al. Early efficacy and safety of Bedaquiline and Delamanid given together in a "Salvage Regimen" for treatment of drug-resistant tuberculosis. Indian Journal of Tuberculosis. 2019;66(1):184-188. Available from: 10.1016/j.ijtb.2019.02.006; https://dx.doi.org/10.1016/j.ijtb.2019.02.006.

[7] Capstick T, Tuberculosis WP. Clinical Pharmacy and Therapeutics. C W, K H, editors. Elsevier; 2019.

[8] Sharma V, Bhagat S, Verma B, Singh R, Singh S. Audiological Evaluation of Patients Taking Kanamycin for Multidrug-Resistant Tuberculosis. Iranian Journal of Otorhinolaryngology. 2016;28(86):203-208.

[9] Chhabra P; 2019.

[10] Prasad R, Singh A, Kushwaha RS, Srivastava R, Giridhar B, Balasubramanian V, et al. Treatment outcome of multidrug-resistant tuberculosis with modified DOTS-plus strategy: A 2 years' experience. Lung India. 2019;36(5):384-384. Available from: 10.4103/lungindia. lungindia_475_18;https://dx.doi.org/10.4103/lungindia.lungindia_475_18.

[11] Wang SI, Shen GH, Shi HC, Chiou SJ. Prescription patterns for tuberculosis treatment and adherence to treatment guidelines: a population-based study in Taiwan. Pharma- coepidemiology and Drug Safety. 2014;23(12):1273-1280. Available from: 10.1002/pds. 3665;https://dx.doi.org/10.1002/pds.3665.

[12] Biradar SM, Joshi CP, Patel G, Kalyane JV, V N, J. Prescribing pattern of anti-tubercular drugs in a tertiary care hospital. World Journal of Pharmaceutical Sciences. 2016;4(5):253-259.

[13] Huang F, Zhang H, Lv Q, Sato KD, Qu Y, Huan S, et al. Use of anti-tuberculosis drugs among newly diagnosed pulmonary tuberculosis inpatients in China: a retrospective study. Infec- tious Diseases of Poverty. 2016;5(1):2-2. Available from: 10.1186/s40249-016-0098- 9; https://dx.doi.org/10.1186/s40249-016-0098-9.

[14] Sulis G, Centis R, Sotgiu G, D'Ambrosio L, Pontali E, Spanevello A, et al.. Recent developments in the diagnosis and management of tuberculosis. Springer Science and Business Media LLC; 2016. Available from: 10.1038/npjpcrm.2016.78;https://dx.doi.org/10. 1038/npjpcrm.2016.78.

[15] Omar AAAH, Mohammad MM, George AA, M. Tuberculosis Situation in El-Minia Governorate (1997-2010) before and after Direct Observed Therapy Short Course Strategy (DOTS). Asian Journal of Medical Principles and Clinical Practice. 2019;2(1):1-10.

[16] Kaur S, Rajagopalan S, Kaur N, Shafiq N, Bhalla A, Pandhi P, et al. Drug Utilization Study in Medical Emergency Unit of a Tertiary Care Hospital in North India. Emergency Medicine International. 2014;2014:1-5. Available from: 10.1155/2014/973578;https://dx.doi.org/10.1155/2014/973578.

[17] Anupurba S, Sinha P, Srivastava GN, Gupta A. Association of risk factors and drug re- sistance 


\section{www.ijppr.humanjournals.com}

pattern in tuberculosis patients in North India. Journal of Global Infectious Diseases. 2017;9(4):139-139. Available from: 10.4103/jgid.jgid_167_16;https://dx.doi.org/ 10.4103/jgid.jgid_167_16.

[18] H Y, K, B K, Prasath KA, H K; 2017.

[19] Reddy MM, Thekkur P, Ramya N, Kamath PBT, Shastri SG, Kumar RBN, et al. To start or to complete? - Challenges in implementing tuberculosis preventive therapy among people living with HIV: a mixed-methods study from Karnataka, India. Global Health Action. 2020;13(1):1704540-1704540. Available from: 10.1080/16549716.2019. 1704540;https://dx.doi.org/10.1080/16549716.2019.1704540.

[20] Zhang H, Ehiri J, Yang H, Tang S, Li Y. Impact of Community-Based DOT on Tuberculosis Treatment Outcomes: A Systematic Review and Meta-Analysis. PLOS ONE.2016;11(2):e0147744e0147744. Available from: 10.1371/journal.pone.0147744;https://dx.doi.org/10.1371/journal.pone.0147744.

[21] Rendon A, Tiberi S, Scardigli A, D’Ambrosio L, Centis R, Caminero JA, et al. Classification of drugs to treat multidrug-resistant tuberculosis (MDR-TB): evidence and perspectives. Journal of Thoracic Disease. 2016;8(10):2666-2671. Available $\quad$ from: $\quad 10.21037 / \mathrm{jtd} .2016$. 10.14;https://dx.doi.org/10.21037/jtd.2016.10.14.

[22] Negm MF, Allam AH, Zeheiry E. Assessment of directly observed therapy short-course (DOTS) of tuberculosis in Dakahlia governorate chest hospitals from. Egyptian Journal of Bronchology. 2006;11(2):88-97.

[23] Piubello A, Harouna SH, Souleymane MB, Boukary I, Morou S, Daouda M, et al. High cure rate with standardised short-course multidrug-resistant tuberculosis treatment in Niger: no relapses. The International Journal of Tuberculosis and Lung Disease. 2014;18(10):1188-1194. Available from: 10.5588/ijtld.13.0075; https://dx.doi.org/10. 5588/ijtld.13.0075.

[24] Xu Y, Wu J, Liao S, Sun Z. Treating tuberculosis with high doses of anti-TB drugs: mechanisms and outcomes. Annals of Clinical Microbiology and Antimicrobials. 2017;16(1):67-67.

[25] Mishra R, Krishan S, Siddiqui AN, Kapur P, Khayyam KU, Sharma M. Potential role of ad- juvant drugs on efficacy of first line oral antitubercular therapy: Drug repurposing. Tuber- culosis. 2020;120:101902-101902. Available from: 10.1016/j.tube.2020.101902;https://dx.doi.org/10.1016/j.tube.2020.101902.

[26] O\&apos;brien R, Spigelman M. New Drugs for Tuberculosis: Current Status and Future Prospects. Clinics in Chest Medicine. 2005;26(2):327-340.

[27] Tiberi S, Muñoz-Torrico M, Duarte R, Dalcolmo M, D’Ambrosio L, Migliori GB. New drugs and perspectives for new anti-tuberculosis regimens. Pulmonology. 2018;24(2):86-98. Available from: 10.1016/j.rppnen.2017.10.009; https://dx.doi.org/10.1016/j.rppnen. 2017.10.009.

[28] Bahuguna A, Rawat DS. An overview of new antitubercular drugs, drug candidates, and their targets. Medicinal Research Reviews. 2020;40(1):263-292. Available from: 10. 1002/med.21602;https://dx.doi.org/10.1002/med.21602.

[29] Pontali E, Sotgiu G, D’Ambrosio L, Centis R, Migliori GB. Bedaquiline and multidrug-resistant tuberculosis: a systematic and critical analysis of the evidence. European Respiratory Journal. 2016;47(2):394402. Available from: 10.1183/13993003.01891- 2015;https://dx.doi.org/10.1183/13993003.01891-2015.

[30] Lakshmanan M, Xavier AS. Bedaquiline - The first ATP synthase inhibitor against multi drug resistant tuberculosis. Journal of Young Pharmacists. 2013;5(4):112-115. Available from: 10.1016/j.jyp.2013.12.002; https://dx.doi.org/10.1016/j.jyp.2013.12.002.

[31] Salinger DH, Nedelman JR, Mendel C, Spigelman M, Hermann DJ. Daily Dosing for Bedaquiline in Patients with Tuberculosis. Antimicrobial Agents and Chemotherapy. 2019;63(11). Available from: 10.1128/aac.00463-19; https://dx.doi.org/10.1128/aac. 00463-19.

[32] Zhurkin D, Gupta RK, Gadoev J, Dadu A, Davtyan K, Hurevich H. Effectiveness and safety of bedaquiline-containing regimens among adults with multidrug- or extensively drug- resistant pulmonary TB in Belarus: a nationwide cohort study. Public Health Panorama. 2019;5(4):369-613.

[33] Pontali E, D’Ambrosio L, Centis R, Sotgiu G, Migliori GB. Multidrug-resistant tuberculosis and beyond: an updated analysis of the current evidence on bedaquiline. European Respiratory Journal. 2017;49(3):17001461700146. Available from: 10.1183/13993003. 00146-2017;https://dx.doi.org/10.1183/13993003.00146-2017.

[34] Gler MT, Skripconoka V, Sanchez-Garavito E, Xiao H, Cabrera-Rivero JL, Vargas-Vasquez D. Delamanid for Multidrug-Resistant Pulmonary Tuberculosis. The New England Journal of Medicine. 2007;366:2151-60.

[35] Karekar SR, Marathe P. Current Status of Delamanid in the Management of MDR Tuber- culosis. Journal 


\section{www.ijppr.humanjournals.com}

of The Association of Physicians of India. 2018;66:72-75.

[36] Sloan D, Lewis J. The role of delamanid in the treatment of drug-resistant tuberculosis. Therapeutics and

Clinical Risk Management. 2015;11:779-779. Available from: 10.2147/ tcrm.s71076; https://dx.doi.org/10.2147/tcrm.s71076.

[37] Imam F, Sharma M, Khayyam KU, Al-Harbi NO, Rashid MK, Ali MD, et al. Adverse drug reaction prevalence and mechanisms of action of first-line anti-tubercular drugs. Saudi Pharmaceutical Journal. 2020;28(3):316-324. Available from: 10.1016/j.jsps.2020.01. 011;https://dx.doi.org/10.1016/j.jsps.2020.01.011. [38] Mafukidze AT, Calnan M, Furin J. Peripheral neuropathy in persons with tuberculosis. Elsevier BV; 2016. Available from: 10.1016/j.jctube.2015.11.002;https://dx.doi.org/10. 1016/j.jctube.2015.11.002.

[39] Prasad R, Singh A, Srivastava R, Hosmane GB, Kushwaha RAS, Jain A. Frequency of adverse events observed with second-line drugs among patients treated for multidrug-resistant tuberculosis. Indian Journal of Tuberculosis. 2016;63(2):106-114. Available from: 10.1016/j.ijtb.2016.01.031;https://dx.doi.org/10.1016/j.ijtb.2016.01.031.

[40] Madhav B, Lyer A, Jayalakshmi TK. Side effect profile of 2 line drugs in multi drug resistant (MDR) and extensively drug resistant (XDR) tuberculosis. European Respiratory Journal. 2015;46(59).

[41] Hire DRC, Kale DAS, Dakhale DGN, Gaikwad DNN. A Prospective, Observational Study of Adverse Reactions to Drug Regime for Multi-Drug Resistant Pul- Monary Tuberculosis in Central India. Mediterranean Journal of Hematology and Infectious Diseases. 2014;6(1):e2014061-e2014061. Available from: 10.4084/mjhid. 2014.061; https://dx.doi.org/10.4084/mjhid.2014.061.

[42] Pontali E, Sotgiu G, Tiberi S, D’Ambrosio L, Centis R, Migliori GB. Cardiac safety of be- daquiline: a systematic and critical analysis of the evidence. European Respiratory Journal. 2017;50(5):1701462-1701462. Available from: 10.1183/13993003.01462-2017;https://dx.doi.org/10.1183/13993003.01462-2017.

[43] Guglielmetti L, Tiberi S, Burman M, Kunst H, Wejse C, Togonidze T, et al. QT prolongation and cardiac toxicity of new tuberculosis drugs in Europe: a Tuberculosis Network European Trials group (TBnet) study. European Respiratory Journal. 2018;52(2):1800537-1800537. Available from: 10.1183/13993003.005372018;https://dx.doi.org/10.1183/13993003. 00537-2018.

[44] Mirlohi MS, Ekrami A, Shirali S, Ghobeishavi M, Pourmotahari F. Hematological and liver toxicity of anti-tuberculosis drugs. Mehr Publishing Group; 2016. Available from: 10. 19082/3005; https://dx.doi.org/10.19082/3005.

[45] Sarkar S, Ganguly A. Current Overview of Anti-Tuberculosis Drugs: Metabolism and Toxicities. Mycobacterial Diseases. 2016;6(2):1-5. Available from: 10.4172/2161-1068. 1000209;https://dx.doi.org/10.4172/2161-1068.1000209.

[46] K E, V. Tuberculosis as a Reason for Male and Female Sexual Dysfunction. Annals of Infections and Antibiotics. 2017;1:101-101.

[47] Mathews B, Thalody AA, Miraj SS, Kunhikatta V, Rao M, Saravu K. Adverse Effects of Fluoroquinolones: A Retrospective Cohort Study in a South Indian Tertiary Healthcare Facility. Antibiotics. 2019;8(3):104-104. Available from: 10.3390/antibiotics8030104;https://dx.doi.org/10.3390/antibiotics8030104. [48] Roberts J. Adverse Reactions to Fluoroquinolones. Emergency Medicine News. 2008;30(10):1618.

[49] Saraf G, Akshata JS, Kuruthukulangara S, Thippeswamy H, Reddy SK, Buggi S, et al. Cy- closerine induced delirium during treatment of multi-drug resistant tuberculosis (MDR- TB). Egyptian Journal of Chest Diseases and Tuberculosis. 2015;64(2):449-451. Available from: 10.1016/j.ejcdt.2014.11.032;https://dx.doi.org/10.1016/j.ejcdt.2014.11.032.

[50] Palomino J, Martin A. Drug Resistance Mechanisms in Mycobacterium tuberculosis. Antibi- otics. 2014;3(3):317-340. Available from: 10.3390/antibiotics3030317;https://dx.doi. org/10.3390/antibiotics3030317.

[51] Jnawali H, Ryoo S; $2013 . \quad$ Available from: https://www.intechopen.com/books/ tuberculosis-current-issues-in-diagnosis-and-management/first-and-second-line-drugs- and-drug-resistance. [52] Padma T; 2019. Available from: https://www.natureasia.com/en/nindia/article/10.1038/ nindia.2019.150.

[53] Stagg HR, Lipman MC, McHugh TD, Jenkins HE. Isoniazid-resistant tuberculosis: a cause for concern? The International Journal of Tuberculosis and Lung Disease. 2017;21(2):129-139. Available from: 10.5588/ijtld.16.0716; https://dx.doi.org/10. 5588/ijtld.16.0716. 


\section{www.ijppr.humanjournals.com}

[54] Ahmad N, Javaid A, Sulaiman SAS, Ming LC, Ahmad I, Khan AH. Resistance patterns, prevalence, and predictors of fluoroquinolones resistance in multidrug resistant tuberculosis patients. The Brazilian Journal of Infectious Diseases. 2016;20(1):41-47. Available from: 10.1016/j.bjid.2015.09.011;https://dx.doi.org/10.1016/j.bjid.2015.09.011.

[55] Deun AV, Maug AKJ, Salim MAH, Das PK, Sarker MR, Daru P, et al. Short, Highly Effective, and Inexpensive Standardized Treatment of Multidrug-resistant Tuberculosis. American Journal of Respiratory and Critical Care Medicine. 2010;182(5):684-692. Available from: 10.1164/rccm.2010010077oc;https://dx.doi.org/10.1164/rccm.201001-0077oc.

[56] Hamusse SD, Teshome D, Hussen MS, Demissie M, Lindtjørn B. Primary and secondary anti-tuberculosis drug resistance in Hitossa District of Arsi Zone, Oromia Regional State, Central Ethiopia. BMC Public Health. 2016;16(1):593-593. Available from: 10.1186/ s12889-016-3210-y;https://dx.doi.org/10.1186/s12889-0163210-y.

[57] Falzon D, Gandhi N, Migliori GB, Sotgiu G, Cox HS, Holtz TH, et al. Resistance to fluoroquinolones and second-line injectable drugs: impact on multidrug-resistant TB outcomes. European Respiratory $\begin{array}{lllll}\text { Journal. } & 2013 ; 42(1): 156-168 . & \text { Available } & \text { from: } & 1183 / 09031936 .\end{array}$ 00134712; https://dx.doi.org/10.1183/09031936.00134712.

[58] Seung KJ, Keshavjee S, Rich ML. Multidrug-Resistant Tuberculosis and Extensively Drug-Resistant Tuberculosis. Cold Spring Harbor Laboratory; 2015. Available from: 10.1101/ cshperspect.a017863;https://dx.doi.org/10.1101/cshperspect.a017863.

[59] Nunn A, Phillips P, Meredith S, Chiang C, Conradie F, Dalai D. A Trial of a Shorter Regimen for Rifampin-Resistant Tuberculosis. New England Journal of Medicine. 2019;380(13):1201-1213.

[60] Lee M, Lee J, Carroll MW, Choi H, Song MS, T. Linezolid for Treatment of Chronic Extensively Drug-Resistant Tuberculosis. The New England Journal of Medicine. 2012;367(16):1508-1518.

[61] Lemos ACM, Matos ED. Multidrug-resistant tuberculosis. Elsevier BV; 2013. Available from: 10.1016/j.bjid.2013.01.007;https://dx.doi.org/10.1016/j.bjid.2013.01.007.

[62] Goyal V, Kadam V, Narang P, Singh V. Prevalence of drug-resistant pulmonary tuberculosis in India: systematic review and meta-analysis. BMC Public Health. 2017;17(1):817- 817. Available from: 10.1186/s12889-017-4779-5;https://dx.doi.org/10.1186/s12889- 017-4779-5.

[63] Méda ZC, Lin YT, Sombié I, Maré D, Morisky DE, Chen YMA. Medication-adherence predictors among patients with tuberculosis or human immunodeficiency virus infection in Burk- ina Faso. Journal of Microbiology, Immunology and Infection. 2014;47(3):222-232. Available from: 10.1016/j.jmii.2013.05.001; https://dx.doi.org/10.1016/j.jmii.2013.05.001.

[64] Boru CG, Shimels T, Bilal AI. Factors contributing to non-adherence with treatment among TB patients in Sodo Woreda, Gurage Zone, Southern Ethiopia: A qualitative study. Journal of Infection and Public Health. 2017;10(5):527-533. Available from: 10.1016/j.jiph.2016. 11.018;https://dx.doi.org/10.1016/j.jiph.2016.11.018. [65] Gelaw SM. Socioeconomic Factors Associated with Knowledge on Tuberculosis among Adults in Ethiopia. Tuberculosis Research and Treatment. 2016;2016:1-11. Available from: 10.1155/2016/6207457;https://dx.doi.org/10.1155/2016/6207457.

[66] Kigozi NG, Heunis JC, Engelbrecht MC, van Rensburg APJ, van Rensburg HCJD. Tuberculosis knowledge, attitudes and practices of patients at primary health care facilities in a South African metropolitan: research towards improved health education. BMC Public Health. 2017;17(1):798-798. Available from: 10.1186/s12889-017-4825-3;https://dx.doi.org/10.1186/s12889-017-4825-3.

[67] van der Werf MJ, Langendam MW, Huitric E, Manissero D. Knowledge of tuberculosis- treatment prescription of health workers: a systematic review. European Respiratory Journal. 2012;39(5):1248-1255. Available from: 10.1183/09031936.00125611; https://dx.doi.org/10.1183/09031936.00125611.

[68] Pramanik D, Ghosh JR. Knowledge and Awareness of Tuberculosis Among Pulmonary Tuberculosis Patients in a Rural Area of West Bengal. SAARC Journal of Tuberculosis, Lung Diseases and HIV/AIDS. 2016;12(2):13-19. Available from: $\quad$ 10.3126/saarctb.v12i2. 15950; https://dx.doi.org/10.3126/saarctb.v12i2.15950.

[69] Singla N, Sharma PP, Singla R, Jain R; 1998.

[70] Rabin AS, Kuchukhidze G, Sanikidze E, Kempker RR, Blumberg HM. Prescribed and self-medication use increase delays in diagnosis of tuberculosis in the country of Georgia. The International Journal of Tuberculosis 


\section{www.ijppr.humanjournals.com}

and

Lung

Disease.

2013;17(2):214-220.

Available

from:

10.5588/ijtld.12.0395;https://dx.doi.org/10.5588/ijtld.12.0395.

[71] Mukerji R, Turan JM. Exploring Manifestations of TB-Related Stigma Experienced by Women in Kolkata,

India. Annals of Global Health. 2018;84(4):727-727. Available from: 10.29024/aogh.2383; https://dx.doi.org/10.29024/aogh.2383.

[72] Schacht CD, Mutaquiha C, Faria F, Castro G, Manaca N, Manhiça I, et al. Barriers to access and adherence to tuberculosis services, as perceived by patients: A qualitative study in Mozambique. PLOS ONE. 2019;14(7):e0219470-e0219470. Available
journal.pone.0219470; $\mathrm{https://dx.doi.org/10.1371/journal.pone.0219470.}$

[73] Pai M, Bhaumik S, Bhuyan SS. India's plan to eliminate tuberculosis by 2025: converting rhetoric into reality. BMJ Global Health. 2017;2(2):e000326-e000326. Available from: 10.1136/bmjgh-2017000326;https://dx.doi.org/10.1136/bmjgh-2017-000326.

[74] Singh S, Kumar S. Tuberculosis in India: Road to elimination. International Journal of Preventive Medicine. 2019;10(1):114-114.

[75] Available fro m:

http://www.euro.who.int/en/health-topics/communicable-

diseases/tuberculosis/data-and-statistics/challenges-for-tuberculosis-tb-control-in-the- european-region.Jain R.

Tuberculosis- Challenges and Opportunities Indian Journal of Tuberculosis. 2011;58:148-154.

[76] Dias HY, Pai M, Raviglione M. Ending tuberculosis in India: A political challenge \& an opportunity. Indian Journal of Medical Research. 2018;147(3):217-217. Available from: 10.4103/ijmr.ijmr_660_18;https://dx.doi.org/10.4103/ijmr.ijmr_660_18.

\begin{tabular}{|l|l|}
\hline & $\begin{array}{l}\text { Dr. Ashish Akshay Bedi (Pharm D, Rph, BLS, ACLS) } \\
\text { Assistant Professor \& Clinical Preceptor } \\
\text { Teerthanker Mahaveer University, Moradabad, Uttar } \\
\text { Pradesh }\end{array}$ \\
\hline $\begin{array}{l}\text { Kaivalya R Pillai } \\
\text { Research Scholar } \\
\text { Teerthanker Mahaveer University, Moradabad, Uttar } \\
\text { Pradesh }\end{array}$ \\
\hline $\begin{array}{l}\text { Pankhuri Jain } \\
\text { Research Scholar } \\
\text { Teerthanker Mahaveer University, Moradabad, Uttar } \\
\text { Pradesh }\end{array}$ \\
\hline $\begin{array}{l}\text { Hashim Khan } \\
\text { Research Scholar } \\
\text { Teerthanker Mahaveer University, Moradabad, Uttar } \\
\text { Pradesh }\end{array}$
\end{tabular}

